\title{
ANTICIPATION OF OPERATING PROBLEMS
}

\author{
IN THE DESIGN OF
}

HEAT TRANSFER EQUIPMENT

Karl A. Gardner

Liquid Metal Engineering Center ${ }^{*}$

\begin{abstract}
This report NOTE
This repost was repared as an account of work

the United States United States Government. Neither

Commission States nor the United States Atomic Energy their contion, nor any of their employees, nor any of their contractors, subcontractors, or their employees, makes any warranty, express or implied, or assumes any logai liability or responsibility for the accuracy, completeness or usefulness of any information, apparatus, would not infringe privately, or represents that its use would not infringe privately owned rights.
\end{abstract}

* Operated for the U.S. Atomic Energy Commission by Atomics International, a Division of North American Rockwell Corporation, under Contract A T (04-3)-700. 


\section{ANTICIPATION OF OPERATING PROBLEMS IN THE \\ DESIGN OF HEAT TRANSFER EQUIPMENT}

Karl A. Gardner

\section{INTRODUCTION}

It is the purpose of this presentation to consider possible problems in the operation of heat exchangers, and how to design to avoid them. Many are rather obvious in nature and will be mentioned only in passing, or not at all. Others may be obvious, but difficult to solve, and still others may not be at all apparent; these will be discussed in greater detail, except where more authoritative presentations are known to be scheduled for this 1972 Seminar.

It should not be, but sometimes is, necessary to point out that a heat exchanger is not only an apparatus for transferring heat from one medium to another, but is at the same time a pressure and/or containment vessel. More frequently it is two such vessels combined in an intricate way into a single piece of equipment, with diverse attendant problems. In the United States at least, and probably elsewhere, the rating - i.e., the determination of size and configuration of a heat exchanger - is frequently done by one specialized group of engineers, and the mechanical design assuring its safety and durability as a pressure vessel by another group. Too often members of these two groups are not well versed in one another's problems, and ill-considered compromises arising from failure of communication or understanding lead to inadequacy in service. This is really an organizational and procedural problem, not fundamentally one of design. It is hoped that the remarks which follow will be of some assistance in broadening the mutual areas of understanding between rating and design engineers, not only in industry, but also in academic circles.

The subject matter will be discussed under the broad headings of "Deficiencies in Heat Transfer and Pressure Loss Rating" and "Deficiencies as a Containment and Pressure Vessel." 


\section{DEFICIENCIES IN HEAT TRANSFER AND PRESSURE LOSS RATING}

\section{A. ELEMENTARY CONSIDERATIONS}

Since the rate of heat transfer, $Q$, in a heat exchanger is determined by the simple relationship,

$$
Q=\int_{0}^{A}{ }^{\mathrm{o}} \mathrm{U}_{\mathrm{o}} \Delta t \mathrm{dA}=\mathrm{A}_{\mathrm{o}} \mathrm{U}_{\mathrm{om}} \Delta \mathrm{t}_{\mathrm{m}}
$$

the reason for failure of an exchanger to perform its heat transfer duty is to be sought in either of the two quantities $U_{\text {om' }}$, the mean overall heat transfer coefficient, or $\Delta \mathrm{t}_{\mathrm{m}}$, the mean effective temperature difference between the heat exchanging streams. More properly, since both $U_{0}$ and $\Delta t$ may vary througnout the exchanger, the incorrectly integrated value of their product may be the culprit in a heat transfer deficiency. Nevertheless, it is convenient, and usually adequate, to consider each of $U_{o m}$ and $\Delta t_{m}$ as separately determinable.

The overall coefficient, $U_{0}$, may be expressed in the form:

$$
\frac{1}{U_{0}}=\frac{1}{h_{0}}+\frac{1}{h_{i}}\left(\frac{A_{0}}{A_{i}}\right)+r_{o}+r_{i}\left(\frac{A_{o}}{A_{i}}\right)+r_{w}\left(\frac{A_{o}}{A_{w}}\right),
$$

in which the h's represent heat transfer "film" coefficients, and the r's, heat transfer resistances, referred to the surfaces at which they occur as indicated by subscripts o (outside), $i$ (inside), and $w$ (wall). Multipliers $\left(A_{0} / A_{i}\right.$ ) and $\left(A_{0} / A_{w}\right.$ ) merely refer these values to the outside surface. The quantity, $r_{w}$, is the metal resistance of the tube wall in bare tube equipment, and is seldom susceptible to serious error, except possibly for combinations of boiling, condensing, or liquid metal streams, in which case it may be the major part of the total resistance to heat flow, and an error in tube wall thickness or thermal conductivity may be significant. The fouling resistances, $r_{0}$ and $r_{i}$, will be discussed later. Any one of the h's and r's may be a source of rating error. 
The mean temperature difference is customarily expressed as a multiplier, $F$, times the logarithmic mean of the terminal differences; i.e., $\Delta t_{m}=F \Delta t_{1 \circ g}$. The value of $F$ has been determined for dozens of flow configurations, many of them by myself, based on the as sumptions that $U_{0}$ is constant throughout the exchariger, that the temperatures of both streams vary linearly with the rate of heat exchange, and that all elements of the fluid streams pass over proportional elements of heat transfer surface. One or more of these as sumptions may be, and ofter. is, unwarranted in actual practice.

With these elementary reminders of possible sources of error in raing heat transfer equipment, let us consider some of the most common causes.

\section{B. ERRONEOUS ESTIMATION OF HEAT TRANISFER COEFFICIENTS \\ 1. Inadequate Data}

A common souce of error in heat exchanger rating is the estimation of heat transfer coefficients under conditions for which experimental data are limited in range or completely lacking; e.g., the thermal conductivity of the fluids as a function of temperature, or a new flow configuration. Extrapolation beyond the verified range of data correlations or reasoning by analogy to some related conditions are usually resorted to under such circumstances. There is nothing wrong with this if it is done intelligently, preferably under the guidance of some theoretical approach which is supported by test data over part of the range of variables involved. Extrapolation of empirical straight lines on arithmetic or log-log graph paper passing through a limited range of data is always hazardous, especially in the direction of increasing temperature for physical properties, or in the direction of decreasing Reynolds number for heat transfer or pressure loss correlations.

\section{Erroneous or Misleading Correlations}

Generalized correlations drawing on many sources of data without distinguishing properly between them by clear identifying symbols may give an unwarranted assurance of accuracy in some instances. A familiar example is the graph presented in many texts of the data points, and the curve through them, for the "law of the wall." In many cases the data points are not distinguished from one another and the best line through them is quite well represented, in the turbulent region, by the familiar equation,

$$
\mathrm{u}^{+}=5.5+2.5 \ln \mathrm{y}^{+},
$$


which plots as a straight line on a semilog scale, as shown in Figure 1 . If the data points are identified by Reynolds number, however, and appropriate curves drawn through them, it is seen that they are not straight lines at all but, rather, look like Figure 2. For many purposes, Equation 3 is sufficiently exact, but for others involving derivatives of $\mathrm{u}^{+}$it gives quite misleading results. This example is not directly pertinent to heat exchanger rating, but it does illustrate the point that a composite of undifferentiated data does not necessarily lead to the best correlation, particularly when assembled from different investigators using different models of equipment over different ranges of variables.

\section{FAILURE TO VISUALIZE HEAT VERSUS TEMPERATURE RELATIONSHIPS}

In an exchanger transferring both sensible and latent heat to or from one or both streams, particular care must be taken to determine the appropriate mean temperature difference by breaking the duty into a series of separate, easily calculated, portions. This is illustrated in Figure 3 by an extreme example encountered many years ago. The process involved heating a stream in an exchanger before it entered a reactor in which an exothermic reaction took place; after which the stream, with slightly altered composition, returned counterflow. to itself through the same exchanger. With comfortable terminal temperature differences at both ends of the exchanger, the process engineer had apparently envisioned temperature vs heat removal curves like those shown as solid lines.

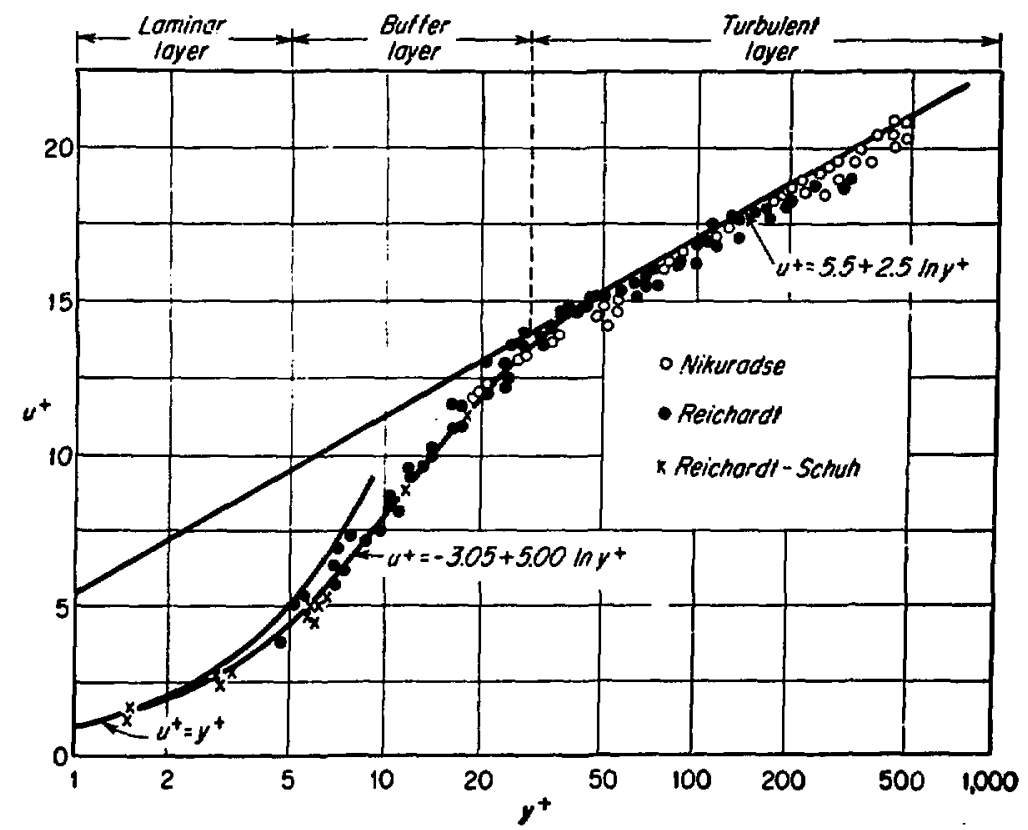

Figure 1. Universal Velocity Distribution for Turbulent Flow in Circular Tubes (from H. Reichardt, NACA TM 1047, 1943) 


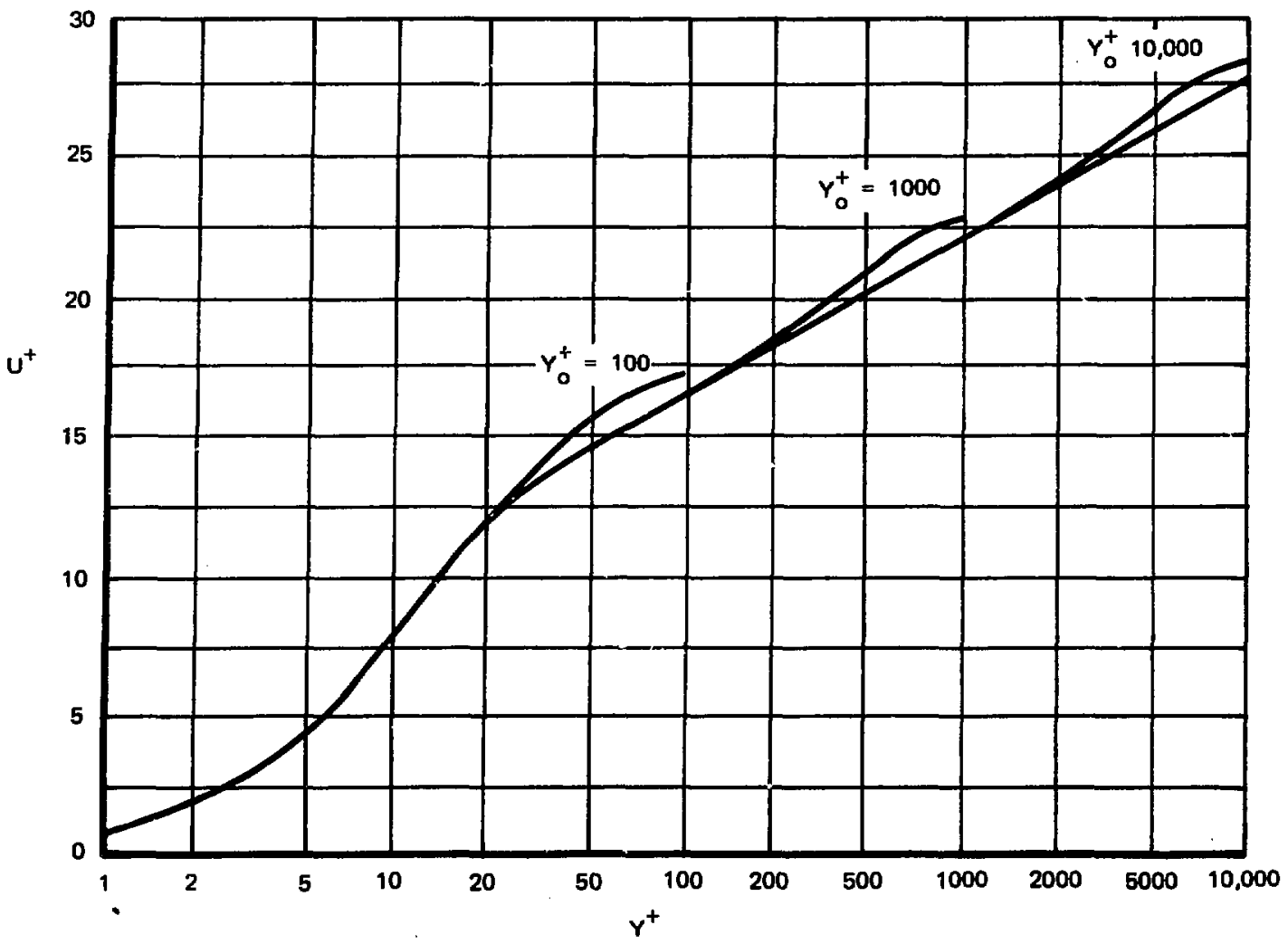

Figure 2. Universal Velocity Distribution for Turbulent Flow in Circular Tubes - Typical Structure when Data Points Plotted with $\mathrm{y}_{0}^{+}$(centerline Value of $\mathrm{y}^{+}$) as a Parameter

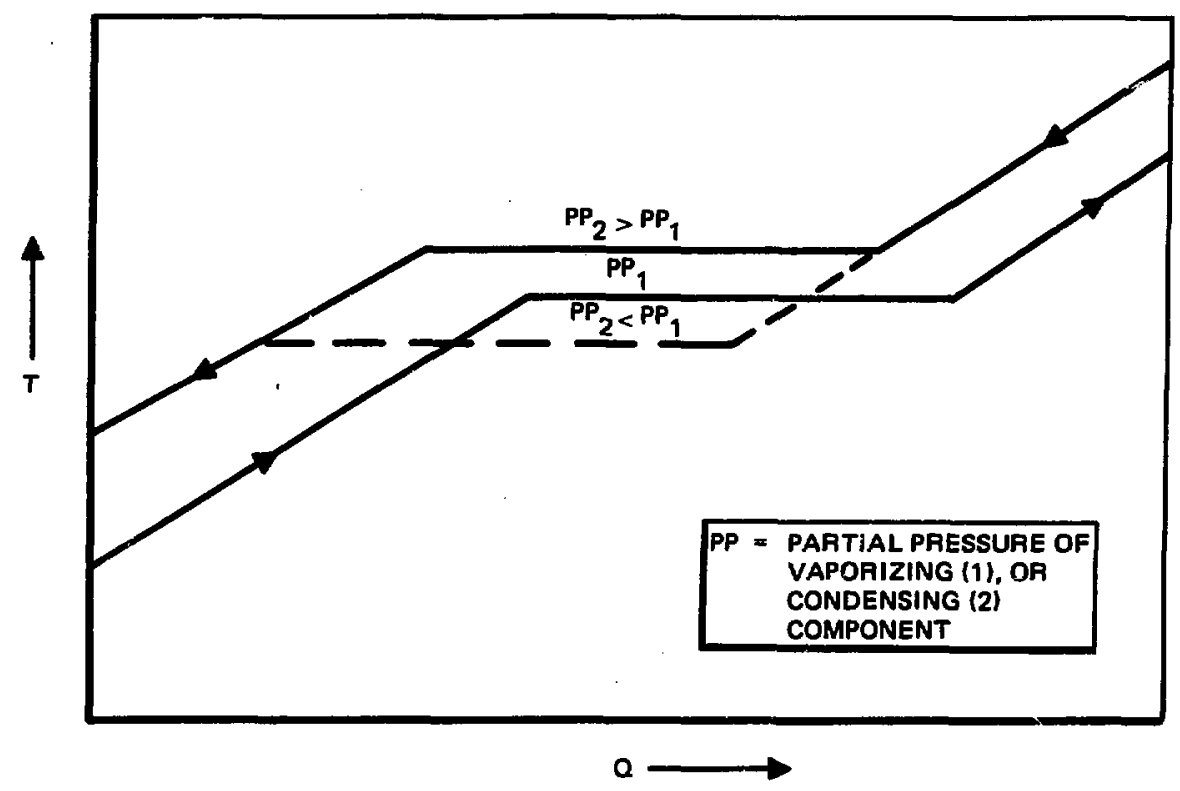

Figure 3. An Impossible Temperature Difference Situation Not Recognizable from the Terminal Values Alone (dashed lines) 
Unfortunately, the pressure loss through the reactor reduced the saturation temperature of the return stream below that of the entering stream as shown by the broken line. The exchanger could not have worked under the conditions specified to the heat exchanger designer because the central isothermal portion had a negative temperature difference between streams.

\section{MALDISTRIBUTION OF F LOW}

If the flow is not uniformly distributed over the heat transfer surface or, still worse, if portions of the stream bypass the surface entirely, there are at least two adverse effects.

First, considering only the case of surface bypassing for purposes of example, the velocity and, hence, the film coefficient, $h_{0}$, are decreased by departure of a portion of the total outside stream from the available flow area through the active tube surface.

Second, the bypass stream reaches the exchanger outlet uncooled (or unheated) in the worst conce:vable case, and only there mixes with the active stream. The resultant outlet temperature, $T_{2}$, is given by

$$
\mathrm{T}_{2}=\mathrm{x} \mathrm{T}_{1}+(1-\mathrm{x}) \mathrm{T}_{2}^{\prime}=\mathrm{T}_{2}^{\prime}+\mathrm{x}\left(\mathrm{T}_{1}-\mathrm{T}_{2}^{\prime}\right)
$$

where $x$ is the fraction bypassed, $T_{1}$ is the inlet temperature, and $T_{2}^{\prime}$ is the outlet temperature of the active stream whose flow fraction is $(1-x)$. Obviously, if the desired heat duty is to be accomplished, $T_{2}^{\prime}$ must be reduced (in the case of cooling) to

$$
T_{2}^{\prime}=T_{2}-\frac{x\left(T_{1}-T_{2}\right)}{(1-x)}
$$

and the effective mean temperature difference may be severely reduced, depending on the magnitudes of the bypass fraction, the cooling range, and the coolant inlet temperature.

These adverse effects on $h_{0}$ and $\Delta t_{m}$ may be drastic in the case of cooling viscous streams, as pointed out by Tinker ${ }^{(1) *}$ more than 20 years ago, since

*Superscripts $r$ efer to the References listed at the end of this treatise. 
the increasing viscosity of the active stream forces more and more of it to take the less viscous bypass route. It is appropriate to include Tinker's well known visualization of the various flow paths here as Figure 4.

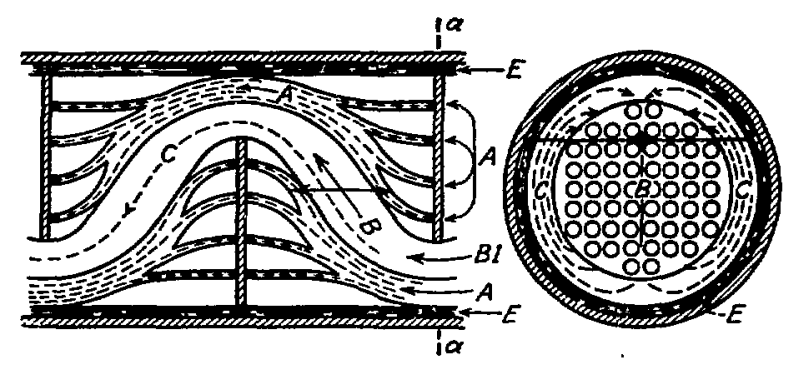

Figure 4. Flow Paths of Various Streams through the Shell of a Cross-Baffled Exchanger (Courtesy of $\mathrm{T}$. Tinker, and American Society of Mechanical Engineers)

The obvious cure for both these undesirable effects is to design so that bypass paths are minimized, especially those between baffle peripheries and the shell (axial bypass), and between the outermost tubes and the shell (cross-flow bypass). Untubed lanes through multi-pass tube bundles necessitated by passpartitions in the heads may, depending on their orientation with respect to flow, also provide bypass paths. The means normally adopted to control bypass are anti-bypass strips or dummy tubes deliberately inserted into the tube layout, and judicious location of tie-rods at the tube bundle periphery.

Another cause of degradation of heat transfer capability due to flow distribution is the existence of stationary eddies (backwaters) which the main stream energizes but does not penetrate or sweep away. Such zones are probably not as prevalent as once thought except where sedimentary or particulate deposits may block the normal fluid escape routes through the annular orifices between baffles and tubes. Under such circumstances, not only the heat transfer coefficient and effective temperature difference suffer, but the pressure loss as well. While the heat exchanger designer may be helpful in minimizing such pockets, the system design should provide for necessary screens, filters, or traps.

\section{E. GAS OR VAPOR BLANKETING IN TWO-PHASE FLOW}

Heat transfer surface may become insulated to varying degrees by accumulation of poorly conducting substances, gaseous or solid. The latter is discussed later under "Fouling." 


\section{Condensing with Noncondensable Gas}

In condensing vapors in the fresence of noncondensable gases, the gas concentration necessarily increases as condensation proceeds. The vapor can arrive at the heat transfer surface only by diffusion through a surface film at a rate dependent upon the difference between its partial pressure in the bulk of the stream and that at the tube wall, and dependent also on the effactive thickness of the film, which varies inversely as a power of the velocity. The resultant gas blanketing toward the condenser outlet may reduce an initial high condensing coefficient almost to zero as the outlet is approached, unless appropriate design measures are taken to maintain a high flow velocity of the gas-rich vapor past the heat transfer surface. It is particularly important to integrate the (U $\Delta t$ ) product carefully in such circumstances.

\section{Vapor Blanketing in Boiling Equipment}

Boiling equipment also may be subject to similar vapor blanketing and insulating phenomena, but for entirely different arıd less well understood reasons sometimes with far more serious results than mere failure to provide the required rate of heat transfer.

One such phenomenon, known variously as "burn-out," "departure from nucleate boiling (DNB)," etc., results from generation of vapor bubbles from closely spaced nucleation sites at such a high volumetric rate compared to the surface on which they are generated that a vapor film is interposed between the surface and the liquid. The consequence is "film boiling," at a vastly reduced heat transfer coefficient as compared to nucleate boiling. This phenomenon is primarily associated with initially high heat flux and may occur even when the bulk temperature of the stream is below saturation temperature.

Film boiling may also be initiated by excessive metal temperature, as may be brought about by momentary deprivation of an adequate liquid supply to the heating surface. This "Leidenfrost effect" prevents a renewed liquid supply from wetting the surface. Dry zones thus created may either heal themselves, increase their extent, or remain stable, depending on the ability (or lack of it) of the surface wall to conduct heat away to adjacent nicleate boiling zones. Thus, unstable flow, whether excursive or periodic in nature, can lead to establishment of film boiling under average flow conditions which, if steady, would not cause departure from nucleate boiling. Once established, film boiling normally persists even though the heat flux, due to the poor coefficient, necessarily rernains much lower than the critical value which may have caused it in the first place. 
Another phenomenon, appropriately termed "dry-out," occurs as vaporization progresses to a point where much of the liquid content of the boiling stream exists in the form of droplets or mist, and the remainder is insufficient to wet the heating surface completely. This is primarily a function of vapor quality, although it varies also with many other parameters, including velocity, presence of centrifugal effects, pressure, and nature of fluid. The result of dry-out is, again, a very poor heat transfer coefficient which partakes of the nature of gas heating and, of course, reduces to a gas heating coefficient as complete vaporization is achieved.

Although much work has been done sirice the advent of the nuclear reactor, it cannot be said that a comprehensive knowledge exists on how to avoid vapor blanketing problems in boiling equipment for all liquids at all pressure, temperature, and flow conditions. In critical applications, recourse must be had to testing of model equipment or, since scaling up from models is not without its hazards, full-scale prototypes. In less critical equipment, liberal factors of safety on all parameters known to increase the likelihood of vapor blanketing are norrnally applied in the absence of actual test data. Examples are the restriction of heat flux to values much lower than can probably be achieved, the deliberate introduction of high pressure loss into the water leg in boilers to avoid unstable flow, and the use of recirculating instead of "once-through" boilers to ensure against the problems of dry-out.

The major undesirable result other than loss of heat transfer capability, referred to earlier in this discussion on boiling, is tube failure caused directly or indirectly by overheat. Thermal stress fatigue caused by alternate local wetting and drying of the tube wall at the indeterminate mobile interface where dry-out occurs is also a matter of concern. This will be considered in greater detail later.

\section{F. FOULING}

Since Dr. J. Taborek, of Heat Transfer Research, Inc. (HTRI), will deliver the next lecture, and later present also a paper on fouling, these remarks will be brief and historical rather than technical. 
There is no need to expound on the fact that practically all nonmetallic solids are characterized by low thermal conductivity, and that if deposited on heat transfer surface by any mechanism whatsoever they constitute a heat transfer resistance, $r_{0}$ and/or $r_{i}$, to the detriment of the overall heat transfer coefficient, $\mathrm{U}_{\mathrm{O}^{-}}$Recognition of this effect first took the form of a "fouling factor," i. e., a multiplier less than unity applied to the overall coefficient for new, clean, equipment to provide some reasonable operating period before the apparatus was no longer capable of handling the specified heat load, and had to be shut down and cleaned. In those days, in view of the state of knowledge on heat transfer coefficients, a considerable component of the "factor" was necessarily a "factor of ignorance." It may be surprising that the phrase "in those days" was applicable into the $1950^{\prime}$ s for some classes of equipment-notably, surface condensers and feedwater heaters, as used in public utility installations.

Other more enlightened users and designers of heat transfer equipment in the chemical and petroleum fields recognized the problem for what it was in the early 1930's, or perhaps sooner - namely, a resistance that should be added in series to the other resistances in the heat flow path. The question then was how much to add for what fluid, at what temperature, at what velocity of flow. Individual users and designers set their own values based on their own experience, or lack thereof. Needless to say, the fouling resistances so chosen differed considerably, even for superficially identical conditions. At the time of my entry into the heat exchanger field in 1936, rating and design of such equipment was very similar to custom tailoring, depending as it did on the desires and whims of individual clients.

The Tubular Exchanger Manufacturers Association ( $T E M A$ ) was founded in the late 1930's in an attempt to establish standards for high-quality shell-andtube heat exchangers which would embrace as many as possible of the requirements of individual users and designers. The first edition of the TEMA Standards $(1941)^{(2)}$ included, among many other things, a listing of recommended fouling resistances for various services. Subsequent editions expanded the list based on such field experience as was available. The fourth (1959) edition, of which I was editor, made clear what should have been obvious from the beginningnamely, that the tabulated values of fouling resistance, constants in most cases, could not possibly be construed as taking into account the many physical and economic considerations necessary for optimization as outlined by Mueller ${ }^{(3)}$ in 1954 in an invited lecture series at Purdue Univerisity. They are, rather, intended as guides to be followed in the absence of other more reliable data. 
A semitheoretical approach to prediction of fouling was suggested in 1959 by D. Q. Kern and R. E. Seaton ${ }^{(4,5)}$ and developed further by Kern in $1966,{ }^{(6)}$ the basis being a deposition rate proportional to the mas flowrate and a suppression rate proportional to the shear of the flowing stream. A conclusion reached by Kern, et al., and also by C. H. Gilmour, (7) was that it is frequently preferable to accept a high pressure loss, with its attendant higher pumping charges, to obtain the benefits of smaller equipment due to the combination of enhanced fluid film coefficient $\left(h_{0}\right.$ and/or $h_{i}$ ) and reduced fouling resistance $\left(r_{o}\right.$ and /or $\left.r_{i}\right)$.

The major scientific investigation of fouling sponsored by HTRI, and carried out in its laboratory and in portable field laboratories, will be discussed by Dr. J. Taborek, as indicated previously. Suffice it to say here that this is, in this speaker's opinion, the most important work currently in progress from the standpoint of economic optimization of heat exchanger selection for specified services.

Fouling, like vapor blanketing, has other adverse effects than loss of heat transfer capabilities, especially when it occurs on the coolant side of highter perature equipment. In this case, tube overheat and failure may be a hazard. Beyond this, porous or spongy deposits may act as concentration cells for corrosive agents which, in combination with a higher corrosion rate at elevated temperature, may also lead to tube failure. Some deposits, however, are beneficial if thin, dense, and uniform. The thin, tightly adherent, magnetite film on steel boiler tubes is a good example in that it protects the underlying metal from the iron-water reaction which would otherwise proceed rapidly, and does so without any serious impedance to heat transfer. Finally, since pressure loss increases inversely as the fifth power of the diameter for flow inside tubes, fouling deposits there may, and often do have a severe adverse effect. The shell-side pressure loss may also be similarly affected.

The obvious cure for fouling problems, aside from that proposed by Kern, et al. , is to eliminate the fouling agent from the stream, but ti:is is not often practicable on process streams since the fluid itself is sometimes the fouling agent through coking or polymerizing reactions. With recirculating streams such as boiler water, jacket water, cooling tower water, and the like, however, there is no reason why fouling cannot be controlled by the user to standards 
imposed by the designer. For sedimenting deposits, the designer may frequently exercise some control over fouling by maintaining high velocity flow and avoiding abrupt changes in flow direction or velocity.

Brittle deposits such as calcium sulfate scale on tubes may be removed periodically in some types of specialized exchangers. If the scale is on the outside of bowed or coiled tubes, occasional thermal shocking will crack it off by flexure or differential thermal expansion. If it is on the inside of vertical tubes, a falling film type of design may be adopted which permits mechanical cleaning while operation continues. (The deposit need not be brittle in this case.)

Scraped surface designs with continuously rotating scraper blades are efficacious in the case of waxy or gelatinous deposits which would otherwise accumulate rapidly.

Beyond these cases, however, the designer can only rely on empirical fouling resistances recommended by TEMA and/or other sources, meanwhile attempting to learn more about the mechanism of fouling in specific circumstances. The knowledge so gained in laboratories and in the field will ultimately make it obvious how the system or component should be designed to minimize the fouling problem.

\section{G. CLOSING REMARKS ON RATING}

Little has been said here which is really new in principle. Leidenfrost's report on nonwetting of hot surfaces, for example, was written (in Latin) in 1756. Most deficiencies in exchanger rating are not due to ignorance of fundamental principles, nor even of lack of adequate data. They are, rather, the result of failure to apply what is known and to make conservative allowance for what is unknown. However, to the extent that provision of more surface than is required may be considered an economic deficiency in rating, these remarks do not apply. 
A vessel designed for the purpose of containing (or excluding) fluids under pressure is quite obviously deficient in its function if any path opens between the interior of the vessel and ambient including, in the case of heat exchangers, paths between one fluid and the other. The result may range in seriousness from a mirior nuisance to near disaster, depending upon the nature of the contained fluids and size and stability of the leakage path. Contrast, for example, the consequences of a leaky gasketed joint in a lubricating oil cooler with a tube rupture in a liquid-sodium-heated steam generator - an untidy spill of water or oil vs an almost explosive chemical reaction, which must be contained.

Various causes of failure and methods for their prevention are considered in what follows.

\section{A. MECHANICAL DESIGN}

1. Pressure Vessel Codes and Standards

Pressure vessels are normally designed for an acceptably safe level of stress at the most severe combination of pressure and temperature anticipated in operation. It is customary to recognize that bending stresses and selfrelieving stresses, such as those caused by restrained thermal expansion, may be permitted higher levels than stresses due to pressure and dead-weight loads, for which no self-relieving mechanism exists.

There are various standards and codes in existence throughout the world for the design of pressure vessels, in which allowable stresses are specified as a function of alloy, metal temperature, and nature of stress, and which also prescribe the design rules for specific vessel components. In the United States, at least, these codes are imposed by the separate states and by some cities, and specified by most individual users. Almost all derive from the Boiler and Pressure Vessel Code of the American Society of Mechanical Engineer (ASME Code). ${ }^{(8)}$ Practically all ordinary pressure vessel components are common with those of heat exchangers, so mechanical design for safety, in view of available codes and standards, is not normally a problem. 


\section{Heat Exchanger Supplements to Pressure Vessel Codes}

There are exceptions or limitations to the design coverage for heat exchangers provided by the codes, mostly from the staridpoint of ruggedness, operabilit and maintainability, rather than that of safety. For example, a flat cover plate may deflect enough under pressure to permit pass-partition gasket bypassing between inlet and outlet compartments of the tube-side stream, even if it is in no danger of failure as a pressure vessel component. The TEMA standards, referred to before, provide design rules supplementing those of the ASME Code for these purposes; so also do the standards of the Heat Exchange Institute (HEI). (9) Both also set forth design rules for tubesheets; thes a are curiously lacking from the ASME Code, but not from other national and international standards, e.g., the British BS-1500, ${ }^{(10)}$ the Dutch Stoomwezen rules, ${ }^{(11)}$ and the forthcoming International Standards Organization (ISO) Pressure Vessel Standards. (11) (There are undoubtedly others with which I am not familiar.)

\section{Differential Thermal Expansion}

A fairly common failing in heat exchanger design is the specification of fixed tubesheets without sufficient thought to the possible consequences in operation. The economic temptation to this design (tubesheets integral with the shell) is considerable, since it is inexpensive compared to the floating head, removable tube bundle, alternatives with the same tube surface. If the shell-side stream is fouling, however, or corrosive, there is no access for thorough inspection or mechanical cleaning, although chemical cleaning may be used for some deposits. (In general, fouling streams should be directed through the tubes, not the shell, in any heat exchanger. Similarly, high-pressure streams should usually be through the tubes to avoid design for collapse. These two rules may occasionally conflict.) The main problem with fixed tubesheet exchangers, of course, is the restraint of free thermal expansion of both shell and tubes which may lead to buckled tubes or slipped tube joints, and ultimate leakage or failure. The use of an expansion joint in the shell will alleviate this situation, but at the risk of suffering a failure of this nonreplaceable part. More often than not, however, difficulties occur in fixed tubesheet exchangers which have no apparent need for expansion joints at the conditions for which they were calculated - normal operating conditions. The trouble usually is that a more severe condition has been overlooked - possibly startup, shutdown, or some process upset or emergency. 
Even floating-head exchangers are not inherently immune to the differential expansion problems just mentioned, since excessive temperature range on the tube side of multipass units may set up similar destructive stresses and/or tube joint loads between adjacent tube passes. Quadrant-type, four-pass tube layouts are particularly susceptible to this difficulty, since the hottest and coldest tube passes are next to one another. The same condition in fixed tubesheet exchangers, of course, may aggravate a situation which is already marginal. A "rule of thumb" frequently used is that the average metal temperature difference between adjacent tube passes should not exceed $50^{\circ} \mathrm{F}\left(28^{\circ} \mathrm{C}\right)$. Figure 5 illustrates the distinction between "ribbon" flow and quadrant flow, with some postulated average metal temperatures of the tube passes. While the ribbon flow tube pass arrangement does not violate the $50^{\circ} \mathrm{F}$ limitation, the quadrant layout exceeds it by a factor of three; the mixed flow arrangement exceeds it by a factor of two.

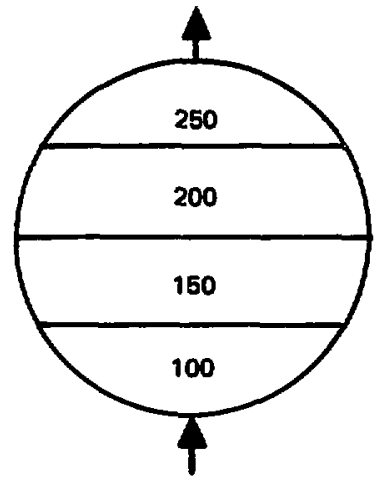

RIBBON FLOW

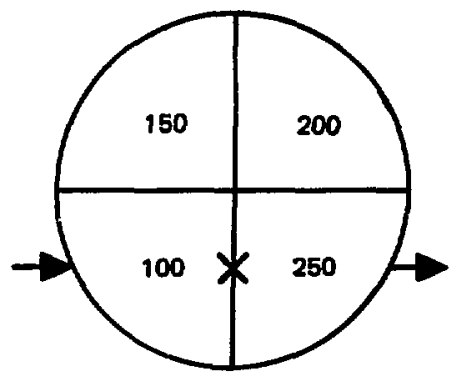

QUADRANT FLOW

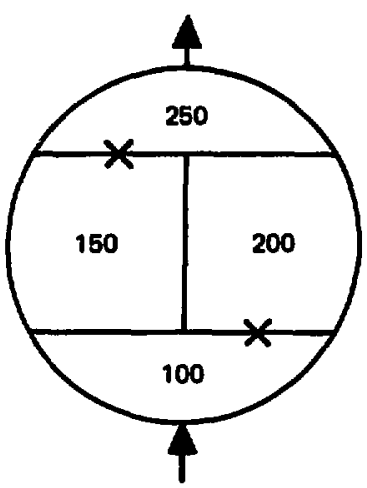

MIXED FLOW

Figure 5. Various Four-Pass Tube Layouts, Showing Undesirable Juxtaposition of Hot and Cold Passes for Quadrant and Mixed Quadrant and Ribbon Flow (x)

\section{Vibration}

A serious cause of heat exchanger failure as a pressure vessel is vibration of its components, most particularly of its tubes. This may lead to failure by fatigue due to the attendant cyclic stress reversals, or to thinning of component walls by fretting wastage as a result of impact or rubbing of parts in contact with one another, such as tubes within baffle holes. The vibration may be mechanically transmitted from other sources, as may happen during shipment or in shipboard or other compact machinery installations where the carrier may be a common supporting structure or the piping to rotating or reciprocating machinery. It may also be fluid transmitted, as in the pulsating stream from a reciprocating compressor. Finally, and most worrisome, vibration may be induced within the exchanger itself by a perfectly steady flow. 
Flow-induced vibration is worrisome because it is not thoroughly understood, although much has been done within recent years, both theoretically and experimentally, to elucidate the phenomena involved, of which there are several. Most familiar is the alternate shedding of eddies from the downstream side of tubes and other obstacles in the flow stream, with resultant periodically alternating lift and drag forces on the obstacles. Whether the eddies have the nature of the von Karman vortices shed by single cylinders in a stream when multiple cylinders are involved, as in a tube bundle, is not so important as the demonstrated facts that:

1) Periodic forces are exerted on the tubes in tube bundles above same minimum Reynolds number.

2) The frequency of these forces increases linearly with the cross-flow velocity over a wide range of Reynolds numbers, thus implying the constancy of the dimensionless Strouhal number, $S=\left(\nu \mathrm{d}_{0} / \mathrm{V}\right)$, in which $\nu$ is the frequency, $V$ the flow velocity, and $d_{0}$ the outside diameter of the tubes. Although the Strouhal number is essentially independent of the Reynolds number up to approximately 200,000, it does depend on the tube arrangement and the spacing-diameter ratios in the transverse and longitudinal flow directions as shown by $\mathrm{Chen}^{(13)}$ and Gregorig and co-workers. $(14,15,16)$ The Strouhal number itself may range from 0.1 to 0.5 , but for customary tube layouts the range is of the order of 0.2 to 0.3 .

3) As the Reynolds number is increased above approximately 200,000 , the energy associated with periodic eddy shedding becomes overshadowed by the increasing turbulent energy over a wide spectrum of frequencies and ultimately becomes imperceptible. The random buffeting of turbulent eddies near the natural frequency of the tubes, however, is still capable of exciting tube vibration and increasing its amplitude with increasing intensity of turbulence.

The vibrational amplitude, and hence the potential for causing damage, is a function of the forcing frequency, the tube natural frequency, the degree of damping, and the static deflection under a steady load of the same magnitude as the maximum of the periodically varying applied load. Figure 6, from den Hartog, shows in dimensionless form the nature of the relationship between these variables. 
THE SINGLE-DEGREE-OF-FREEDOM BYSTEM

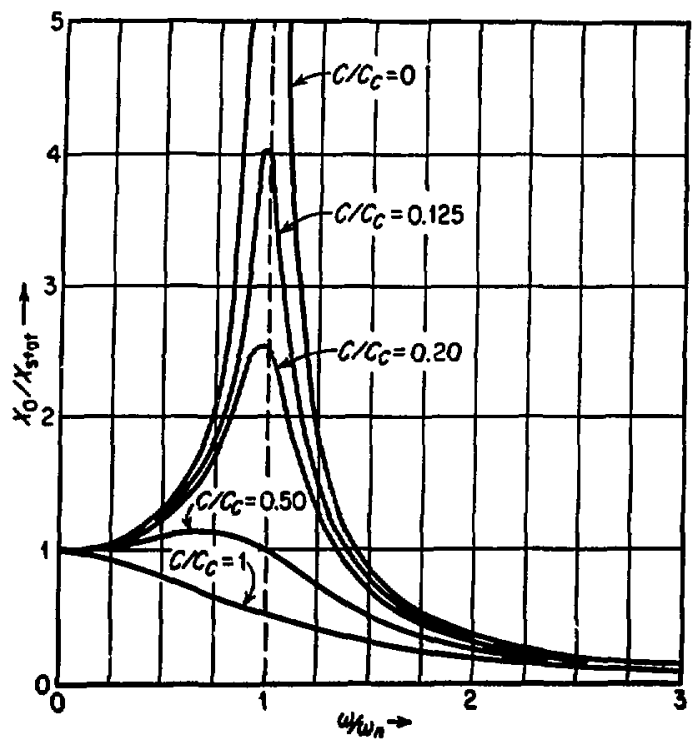

Figure 6. Amplitudes of Forced Tube Vibration for Various Degrees of Damping (den Hartog)

$C$ is a measure of the degree of viscous damping, $C_{c}$ being the value of critical damping above which vibration is not sustained. The ratio shown as abscissa is that of the exciting frequency to the natural frequency. The ordinate gives the ratio of maximum amplitude to static deflection.

Inspe: :on of Figure 6 makes clear in a quantitative manner the well known fact that a resonant condition exists when the forcing and natural frequencies are nearly the same, and that such a situation is to be avoided at all costs unless a high degree of damping is available. For a heat exchanger subject to variable flowrate, it is also seen that it is desirable that the forcing frequency be less than, say, $75 \%$ of the tube natural frequency, and preferably less. This is not to say that operation at $125 \%$, or more, would necessarily be any more hazardous, although a higher harmonic of the tube frequency might be excited. Nevertheless, to reach $125 \%$ it is necessary to pass through $100 \%$ as the flow is brought up to full load and, if steady operation at part load is required, it could readily fall at a resonant condition.

If the maximum cross-flow velocity is known, the forcing frequency is readily determined from the Strouhal number appropriate to the tube layout, thus:

$$
v=s \mathrm{v} / \mathrm{d}_{0}
$$


One difficulty is that $\mathrm{V}$ cannot be determined accurately without some sort of stream analysis. (Of course, if the full stream is assumed to go in cross-flow between adjacent baffles, and the resultant frequency is still sufficiently less than the tubes' natural frequency, this problem does not exist.)

The tube natural frequency is given by:

$$
v_{0}=\frac{\mathrm{C}_{1}}{\mathrm{P}^{2}} \sqrt{\frac{\mathrm{EIg_{c }}}{\mathrm{m}}},
$$

where

$$
\begin{aligned}
& \mathbf{P}=\text { baffle spacing } \\
& \mathbf{E}=\text { elastic modulus of tube material } \\
& \mathbf{I}=\text { moment of inertia of the tube cross section } \\
& \mathbf{g}_{\mathbf{c}}=\text { gravitational constant } \\
& \mathbf{m}=\text { mass per unit length of tube wall, tube contents, and virtual mass of } \\
& \quad \text { the shell fluid, }
\end{aligned}
$$

all in consistent units. The constant, $C$, is normally taken as 1.57 for the tube spans between adjacent baffles and 2.45 for the spans between end baffles and tubesheets, considered, respectively, as simply supported at both ends, and built in at one end and simply supported at the other. These values are for the first mode only.

Other things being equal, the cross-flow velocity in Equation 6 varies inversely as the baffle spacing, $P$, and so does the forcing frequency, $v$. Since the natural frequency, $v_{0}$, varies inversely as $P$ squared, the frequency ratio of interest for use in Figure 6, $v / \nu_{0}$, varies directly as $P$. All other things are not equal, however, because the fraction of the total shell stream which goes in cross-flow decreases as $P$ decreases, but not in a directly proportional fashion. Thus, to decrease $v / v_{0}$ by a factor of two does not require halving the baffle spacing. Frequently the reduction of $P$ is unacceptable because of the increased pressure loss which results; in such cases recourse must be had to other baffle arrangements, as will be discussed later. 
With the foregoing rather oversimplified background information, consideration may be given to some of the options available to the designer to avoid vibration problems. For mechanically or fluid-transmitted vibrations, the choice of baffle spacing and clearances normally provide sufficient freedom in determining the natural frequency of the tubes and their maximum deflection. The latter can also be reduced by alternating the natural frequency of adjoining tube spans by using nonuniform baffle spacing so that each tube span exerts a snubbing influence on its neighbors. For flow-induced vibration, a brief historical comment will be of interest.

Whatever vibration problems that may have existed in the infancy of the heat exchanger industry had been essentially eliminated by restraints imposed on maximum unsupported tube spans and tube-to-baffle clearances. These were codified by the TEMA standards ${ }^{(2)}$ at a time when shell diameters of exchangers rarely exceeded $40 \mathrm{in.} \mathrm{(1000} \mathrm{mm})$. The rules adopted were basically empirical, and no velocity restraints were imposed. Nevertheless, the rules worked and tube vibration problems were very seldom encountered over a period of 20 or more years.

In the early $1950^{\prime} \mathrm{s}$, for the first time, the nuclear power industry demanded the transfer of vast flows of heat, not through water tube boilers as in the past, but through heat exchangers. As a result, in order to reduce the number of shells required, the diameters of the heat exchangers designed increased by a factor of 2 or more, i.e., to 80 to $100 \mathrm{in.} \mathrm{(2000} \mathrm{to} 2500 \mathrm{~mm}$ ). The designers, as often as not, were architect-engineer employees without previous experience or intuitive sense of propriety in design. The trouble began in the late 1950's as these items of equipment finally came into operation at specified flowrates, whereupon a disturbing incidence of tube failures by vibration became evident.

Time and space do not permit pursuing this size effect on vibration in detail. The basic reason for the problem was, however, that years of essentially trouble-free operation of small to medium-sized exchangers - with little or no thought to velocity limitations - had led to an unwar ranted sense of security in relying only on the TEMA-specified maximum unsupported tube spans. The greatly increased flows per shell necessitated considerably greater velocities with this constraint on baffle spacing, and the ratios of $\nu / v_{0}$ approached or passed the critical value of unity. 
One method of reducing cross-flow velocities, and hence exciting frequencies, is shown in Figure 7. This, and its variants, effectively divides the shell stream into parallel paths within the exchanger, each having only a fraction (in this case, $1 / 2$ ) of the cross-flow velocity it would have with ordinary segment-cut baffles. The net effect is to create a no-flow condition across a chordal (diametral, in this case) plane which has the same effect as an actual partition. This is even more effective in reducing pressure loss, since the number of tube layers crossed is also reduced.

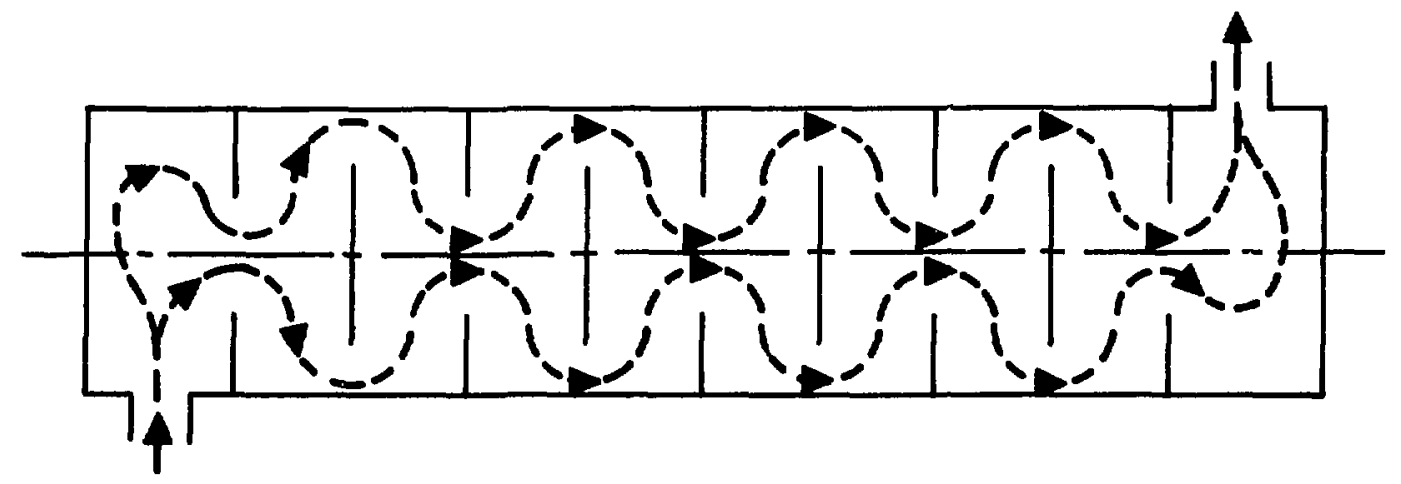

Figure 7. Divided Flow Design to Reduce Cross-Flow Velocities

\section{B. DEFECTIVE MATERIALS AND WORKMANSHIP}

It might be thought that the designer has no control over shortcomings of a heat exchanger as a pressure vessel caused by defective materials or faulty workmanship - that this responsibility rests with the materials vendors and with the fabrication shop. While this may be true in a legalistic sense, the designer's conscience cannot be clear if he has imposed a configuration on the shop or the inspectors which strains the bounds of current technology or nondestructive testing. When design innovations are contracted for, engineering, shop, and inspection departments should all be in agreement that the design is feasible and the integrity of the product verifiable.

\section{SUITABILITY OF MATERIALS TO FLUID ENVIRONMENT}

It is obvious that the materials of construction of heat exchangers should retain their integrity in the fluid environment to which they are exposed, if they are to survive as pressure vessels. Parts such as tubes and floating heads are exposed to two fluids, and a material compatible with both sometimes does not exist. To the extent that oxidation is a problem, similar considerations may apply to external components such as the shell and heads. Loss of integrity may occur in various ways, as discussed in the following. 
1. Wastage

Wastage is a generic term for actual loss of metal encompassing the mechanisms of corrosion, erosion, wear, and fretting, but not degradation of physical properties.

Corrosion reduces the thickness of preasure parts by chemical reaction with an aggressive agent in the ambient fluid(s). It may be uniform in nature, or of the pitting type. If uniform, and at a slow rate, it is often acceptable to use inexpensive materials such as carbon steel with excess thickness of parts, i.e., a corrosion allowance. With pitting corrosion, however, it is necessary either to use a nobler alloy, full thickness or as a cladding, or to treat the fluid to remove the aggressive agent as is done with boiler water treatment, for example. Cladding may of course be used as a substitute for uniform corrosion. allowance. It should be understood that the cladding need not be metallic in all cases; Teflon coatings, or the like, are often used.

Erosion, sometimes abetted by corrosion, involves the physical removal of material by such mechanisms as scouring and cavitation. It is as sociated with areas of high flow velocity and/or sharp changes in flow direction, usually involving two-phase flows. Although some metals have superior erosion resistance, it is seldom warranted to use them for entire components, since erosive effects are so highly localized. I do not feel qualified to offer advice on erosion prevention beyond the obvious items of avoiding high velocities in two-phase streams, providing sacrifical excess material in areas of high velocity impingement, and streamlining entrance regions.

Wear and fretting have been discussed earlier from the standpoint of prevention by controlling vibration by proper design. It may be added here that wastage by these mechanisms is minimized by the use of materials of similar chemical composition and physical hardness for contacting parts susceptible to rubbing and impact. Admiralty metal tubes and commercial brass baffles are compatible from this standpoint; aluminum tubes and steel baffles are not.

\section{Degradation}

Degradation, as used here, refers to the loss of desirable physical properties, such as strength and ductility, without actual loss of material. This can come about by such mechanisms as corrosion embrittlement, mass transfer of alloy constituents, and fatigue, all affecting the metallurgical structure of components. 
Embrittlement is known by many names, in American usage at least, depending upon the alloy affected. With brasses, it is called "season cracking," and with austenitic steels, "intergranular corrosion." Quite low concentrations of corrosive agents, differing from one material to another, are capable of reducing an originally sound ductile material to a mass of weakly joined crystals much like a lump of sugar, and with about as much strength. In ferritic steels, "caustic embrittlement" and "hydrogen embrittlement" have similar effects but, in this case, usually require some concentrating mechanism. Local dry-out in crevices in stressed areas such as tube joints in exchangers will serve this purpose in the case of caustic. Corrosion deposits in an acidic environment set up concentration cells for hydrogen attack.

"Stress corrosion cracking" is another mechanism for degradation, usually associated with austenitic materials but not necessarily confined to these alloys. The failure in this case is by extensive cracking networks, usually transgranular, originating at areas of high tensile stress in the presence of specific corrosive agents above some rninimum concentration. The agent need not be present in the environment at this triggering concentration; crevices, again, often serve to provide the necessary strengthening mechanism. In the case of austenitic steels, chloride ion in the presence of oxygen, or hydroxyl ion, are the most troublesome agents.

As can be seen from what has been said to this point, material degradation as a result of corrosive agents in the environment is best attacked in the design phase by elimination of crevices and pockets where corrosion products can accumulate and, of course, by proper choice of materials.

Mechanical fatigue results from repeated cycling of strain through a range usually, but not necessarily, exceeding twice the strain at yield. The methods for control of vibrational amplitudes, and hence bending strain, have been discussed previously. Thermal fatigue results from repeated excessive strains due to restrained differential expansion within various components of a heat exchanger because of thermal transients in operation. Thermal shields or sleeves are effective in reducing the severity of transients, but obviously cannot be applied to tubes. 
Although seldom encountered, and perhaps peculiar to liquid metal heat transfer systems, the mass diffusion of alloy constituents as a result of thermal gradients should be mentioned under metal degradation. If the system includes both austenitic and low-alloy ferritic material, even though the latter is at a lower temperature, there is a diffusion of carbon out of the ferritic zone into the liquid metal and, from there, into the austenitic zone. The consequence is reduction of strength of the ferritic material and reduction of ductility of the austenitic. The designer should make allowance for this in the permissible stresses or utilize higher alloy ferritic materials less susceptible to carbon transfer.

\section{Crevices and Pockets}

Although it should be amply evident from all that has been said so far, it is worth repeating that no-flow pockets and crevices are to be avoided in design for many reasons. One that has not been mentioned so far is the tendency of some organic streams to coke progressively in hot zones. The build-up of coke in hot tube joints has been known to collapse the tubes in many installations due to its exertion of constantly increasing external pressure. In any instance where tube joints do not require expansion throughout the full tubesheet thickness for the sake of holding power or leak tightness, consideration should be given to a "back-face" expansion to prevent access of the shell fluid to the crevices between tubes and tube hole walls. In many cases it is not a matter of concern; in others, it may be essential.

\section{INTERLEAKAGE OF HEAT EXCHANGING STREAMS}

If contamination or intermixing of one heat-exchanging stream with another must absolutely be avoided for any of various reasons, there are several design options available. Among these are double tubesheets and double wall tubes. The designer, here, attacks the consequences of leakage in addition to normal provisions against leakage. 


\section{Double Tubesheets}

When tube walls are in little danger of failure, but tube joint reliability is mistrusted, the use of closely spaced tubesheets with tubes expanded into both is indicated. The space between them may be used to monitor for leakage of either fluid through the tube joints; in the case of floating heads, at least one tube must be used as communication between the intermediate space at the floating end and that at the stationary end. The possibility of differential radial thermal expansion between both tubesheets of a pair must be given special consideration to assure that this construction does not create more problems than it solves.

\section{Double Tubes}

If both tube walls and tube joints are considered interleakage risks, concentric tubes may be used, each connected to one of the tubesheets of a pair, with monitoring space between tubesheets as described before. Thermal coupling between inner and outer tubes may be by direct metallic contact (with leakage detection grooves), or by an intermediate fluid such as mercury or sodiumpotassium eutectic. Needless to say, these constructions are not often adopted, but both have been used successfully in nuclear steam generators.

One other application of double tubes does not require concentricity, but utilizes instead the conductivity of closely spaced metallic fins into which both tubes are expanded for thermal coupling.

Concentric bimetal tubes may also be the only solution for corrosion problems where no single metal has the necessary resistance to attack by both fluids in a heat exchanger. When used for this purpose, the tubes are drawn down to size together to provide compres sive metal-to-metal contact. In this case double tubesheets are not necessary; instead, the inner tubes are expanded into cladding material on the tube-side faces of the tubesheets. 


\section{CLOSING REMARKS}

In conclusion, it is hoped that this discussion of possible operating difficulties with heat exchangers has been instructive in the aggregate, even though no single topic has been treated in any depth. It should be evident that mastery of heat transfer and fluid mechanics alone is not sufficient to ensure a satisfactory design. Neither is expertise in any one of the several other disciplines involved. Since the individual who is master of them all is rare indeed, a close cooperation and mutual understanding among experts is necessary for all but the most routine design conditions. 


\section{REFERENCES}

1. Tinker, T., "Proceedings of the General Discussion on Heat Transfer," Institution of Mechanical Engineers, London, and American Society of Mechanical Engineers, New York (1951), p 84, 97, 110.

2. "Standards of Tubular Exchanger Manufacturers Association," New York, N. Y. (First, 1941, through Fifth, 1968, Editions).

3. Mueller, A. C., "Thermal Design of Heat Exchangers," Research Series No. 121, Engineering Experiment Station, Purdue University, Lafayette, Indiana (1954), p 47-50.

t. Kern. D. Q., and Seaton, R. E., "A Theoretical Analysis of Thermal Surface Fouling," Brit. Chem. Eng., Vol 4, No. 5 (1959), p 258.

5. Kern, D. Q., and Seaton, R. E., "Surface Fouling, How to Calculate Limits," Chem. Eng. Progress, Vol 55, No. 6 (1959), p 71.

6. Kern, D. Q., "Heat Exchanger Design for Fouling Services," Proceedings of the Third International Heat Transfer Conference, 1966, Vol 1, p 170-i78.

7. Gilmour, C.H., "No Fooling, No Fouling," Chem. Eng. Progress (July 1965), p 61 .

8. "Rules for Construction of Pressure Vessels, ASME Boiler and Pressure Vessel Code, Section VIII," The American Society of Mechanical Engineers, New York, N. Y. (1971).

9. "Heat Exchange Institute Standards for Closed Feedwater Heaters," New York, N. Y., First Edition (1968).

10. "British Standard 1500, Fusion Welded Pressure Vessels," British Standards Institution, London, England (1958).

1 la. "Regulation on Which the Assessment of Construction and Materials of Steam Apparatus, Vapor Apparatus on Pressure Vessels is Based," Staatsuitgeverij, The Hague, Netherlands.

1 lb. "Calculation of Circular Tubesheets of Heat Exchangers With a Fixed and Floating Tubesheet and of Heat Exchangers With Two Fixed Tubesheets," Staatsuitgeverij, The Hague, Netherlands.

12. First Draft Proposal, "Pressure Vessels," International Standards Organization, Document ISO/TC 11 (recr.-76) 248 EF (October 1968).

13. Chen, Y.S., "Flow-Induced Vibration and Noise in Tube-Bank Heat Exchanger Due to von Karman Streets," Trans. ASME, Vol 90, Series B (1968), p 134- 146.

14. Gregorig, R., and Andritzky, H. K. M., "A Criterion for Vibration in Transverse Flow Over a Tube, Part 1," Chem. Ingr. Tech., Vol 39 (1967), p 894-900.

15. Andritzky, H.K. M., and Gregorig, R., "A Criterion for Vibration in Transverse Flow Over a Tube, Part 2,"Chem. Ingr. Tech., Vol 40 (1968), p 483-488.

16. König, A., and Gregorig, R., "A Criterion for Vibration in Transverse Flow Over a Tube, Part 3, Vibration Experiments in the Nest of Tubes," Chem. Ingr. Tech., Vol 40 (1968), p 645-650. 